\title{
A efetividade da participação em fóruns de governança colaborativa da Sabesp: uma proposta teórico- metodológica comparativa
}

Maira Rodrigues*

\section{Resumo}

0 presente trabalho tem como objetivo propor um modelo teórico-metodológico para a avaliação da efetividade da participação social. Para tanto, parte-se da análise de um caso empírico de fóruns de governança colaborativa implementados pela Sabesp em cinco áreas de córregos em São Paulo. Com base no contraste entre duas abordagens, por um lado, a literatura de participação social, e, por outro, a literatura de gestão de bens comuns, são identificadas variáveis estruturais que incidem sobre esses espaços institucionais. 0 argumento é que a combinação das duas literaturas fornece um instrumental mais amplo para a análise dos resultados de cada fórum, em especial no que diz respeito aos atributos do ambiente físico.

\section{Palavras-chave}

Governança colaborativa. Participação social. Institutional Analysis and Development Framework - IAD.

\begin{abstract}
This paper proposes a theoretical and methodological model for evaluating the effectiveness of social participation. It was taken as a starting point the analysis of an empirical case of collaborative governance forums implemented by Sabesp, in five stream areas in São Paulo. Basing the analysis on two contrasting approaches, on the one hand, the literature of social participation and, on the other, the literature of common goods management, structural variables that influences these institutional spaces were identified. The claim is that the combination of the two literatures provides a broader instrumental analysis for the results of each forum, especially regarding to physical environment attributes.
\end{abstract}

\section{Keywords}

Collaborative governance. Social participation. Institutional Analysis and Development Framework - IAD.

\footnotetext{
* Doutoranda do Departamento de Ciência Política da Universidade de São Paulo; e pesquisadora do Núcleo Democracia e Ação Coletiva do Centro Brasileiro de Análise e Planejamento (CEBRAP). E-mail: mairarodrigues@hotmail.com.
} 


\section{Introdução}

A Companhia de Saneamento Básico do Estado de São Paulo - Sabesp empreendeu a criação de fóruns de governança colaborativa em regiões da cidade de São Paulo para maximizar os investimentos na despoluição de córregos. Esses fóruns fazem parte do programa Córrego Limpo, que prevê a despoluição de mais de cem córregos na cidade de São Paulo através da remoção do esgoto despejado irregularmente nesses cursos d'água. Combinada a essa atuação, outra frente de trabalho desse programa é o estabelecimento de parcerias com a população de entorno dos córregos para a perenização dessa política, buscando envolver as lideranças locais bem como os demais moradores, nos esforços de manutenção da limpeza dos córregos e no esclarecimento dos prejuízos ambientais das ligações irregulares de esgoto e da poluição difusa.

Foram selecionadas inicialmente cinco bacias de córregos na cidade de São Paulo, onde foram implementados fóruns de governança colaborativa como projeto-piloto em 2010. O objetivo dos fóruns era duplo: disseminar informações sobre o Programa Córrego Limpo e elaborar projetos de preservação da despoluição realizada pelo programa. A concepção de governança colaborativa empregada se baseou na ideia de gestão compartilhada da despoluição dos córregos como forma de criar envolvimento e colaboração entre diversos atores sociais interessados ou atingidos por ela.

A proposta deste trabalho é fazer a análise dessa governança colaborativa com base em uma proposta teórico-metodológica construída segundo o contraste de duas abordagens que lidam com a participação social em instituições específicas de governança. A partir dessa comparação entre duas literaturas, pretende-se propor uma forma de compreensão da efetividade da participação social empreendida nessas instituições.

Desse modo, esse trabalho se organiza a partir da seguinte estrutura argumentativa. No primeiro item, são apresentados e discutidos os sentidos analíticos de governança. A despeito de o programa analisado fazer uso da expressão governança colaborativa, é preciso distinguir entre a estratégia de envolvimento de atores em uma política pública e a conceituação analítica de governança pela literatura. No item seguinte, é explorado como o sentido amplo de governança também pode abarcar propostas de participação social. Em seguida, aprofunda-se nas experiências de participação social no Brasil contemporâneo, em especial na literatura que tem trabalhado com instituições participativas. O objetivo dessa seção é destacar os elementos 
dessa abordagem, que serão utilizados na avaliação da efetividade dos fóruns implementados pela Sabesp.

No terceiro item, apresenta-se uma outra abordagem da literatura que trabalha com ação coletiva na gestão de bens comuns, em especial o modelo Institutional Analysis and Development Framework - IAD de Elinor Ostrom. Esse modelo serviu de inspiração para a criação dos fóruns de modo que a relação entre o quadro teórico da autora e a política estudada propicia uma rara oportunidade de estudo empírico. O IAD foi elaborado para o estudo da gestão compartilhada, ação coletiva e recursos ambientais - exemplo ideal de bem comum - e por isso é um modelo oportuno para o caso de estudo. Essa seção também tem como objetivo sublinhar as variáveis estruturais que interferem na arena de ação e que farão parte da proposta de avaliação da efetividade.

A quarta parte faz a análise do caso empírico a partir da combinação das duas literaturas, e a quinta avalia a efetividade dos fóruns de governança colaborativa da Sabesp em atingir seus objetivos finais: a elaboração de projetos de preservação ambiental. Por fim, as considerações finais pretendem fazer um balanço sobre os pontos positivos da proposta.

\section{Sentidos analíticos de governança}

Antes de tratar a ideia de governança como um conceito único, vale ponderar que ela tem sido amplamente aplicada em diversos contextos teóricos e empíricos com grande variedade de uso e em uma multiplicidade de áreas de conhecimento. Por esse motivo, é importante entender os usos e debates que envolvem a ideia de governança, para compreender o caso dos fóruns de governança colaborativa da Sabesp. Por isso, os próximos parágrafos são dedicados a uma breve revisão da literatura sobre o tema.

Para Le Galès (2011), a ideia de governança é a capacidade política de grupos de atores agirem para além do Estado. Isto é "um processo de coordenação de atores, grupos sociais e instituições para atingir objetivos particulares, discutir e definir coletivamente em ambientes fragmentados e incertos" (LE GALÈS, 2011, p.748).

Capella (2008) faz um balanço de como o termo aparece no debate atual em várias disciplinas, tanto na área de relações internacionais como pela experiência da formação da União Europeia, como "base institucional para formulação de políticas econômicas" e como "base institucional para o regime 
político democrático" (CAPELLA, 2008, p.3). E no campo da administração pública, com grande complexidade e polêmica, o debate se divide entre usar governança como sinônimo da área, mas também como estratégias de inovações de gestão pública, além da composição de uma agenda de pesquisa exploratória sobre diversos tipos de experiências. São debates em grande parte antagônicos entre si, o que demonstra a plasticidade do termo por se adequar a análises tão distintas entre si.

Por fim, há estudos que não relacionam a ideia de governança a uma teoria, mas à prática contemporânea da gestão pública, relacionando-a aos valores e ideias da Nova Administração Pública ou Administração Pública Gerencial (New Public Management), como resgatada por Pierre (2011) ${ }^{1}$.

A governança também definiria processos através do qual recursos públicos e privados são coordenados na consecução de interesses coletivos (PIERRE, 2011), ou, em uma concepção de amplo acordo, governança seria o "desenvolvimento de estilos de governo no qual fronteiras entre o setor público e privado se tornam borradas" [(STOKER, 1998, p.17 (tradução da autora)]. Assim, a partir dessa noção, a governança traduz estratégias de governo para além do Estado, de inovação institucional e mesmo de ampliação da participação ou de garantia de direitos civis e sociais básicos.

Complementarmente, os usos de governança remetem a incorporação de atores não usuais nas políticas públicas para a discussão e elaboração de propostas (STOKER, 1998), e mesmo para a realização dessas políticas. Eduardo Marques define governança "Como conjunto de atores estatais e não estatais interconectados por relações formais e informais operando no interior do processo de decisão política e integrados em configurações institucionais específicas" [(MARQUES, 2013, p.31 (tradução da autora)].

$\mathrm{Na}$ tentativa de conceber uma conceituação abrangente, poderíamos ressaltar que todas as abordagens examinadas remetem-se a alterações recentes da administração pública a partir de inovações institucionais e de relacionamento entre atores dos setores públicos, privados e societais. Assim, uma definição que articula os principais significados do conceito

\footnotetext{
${ }^{1}$ A escola da New Public Management nasce do debate sobre a reforma administrativa do governo central e com um conjunto de reformas do setor público em muitos países nos anos 1990 . Essas reformas são orientadas por melhorias no serviço público, inspiradas pela eficiência do setor privado, utilizando métodos de privatização e terceirização para ganhar competitividade (PIERRE, 2011). Esse modelo teve grande impacto na administração pública brasileira, seja tanto por debates e formulações no âmbito acadêmico, como por sua influência na orientação de políticas de reforma do Estado empregadas principalmente entre 1995 e 1998.
} 
é pensar em governança como um conjunto de estratégias de inclusão de novos atores nos processos decisórios articulados por instituições de gestão pública ou privada. A partir dessa definição abrangente, a próxima sessão irá mostrar como a participação social pode ser entendida como uma forma de governança.

\section{Governança e participação social no Brasil}

A literatura da América Latina, e em especial a brasileira, que trabalha com o conceito de governança, pode ser agrupada em dois grandes conjuntos opostos, de acordo com Marques (2013). E apesar de essas duas vertentes do debate sobre governança polarizarem a literatura, ambas partilham de perspectivas propositivas sobre governo e relação entre Estado e sociedade, associadas ao reconhecimento de mudanças locais dos governos desde a redemocratização brasileira, com tendências descentralizadoras e democráticas. De acordo com o autor, as duas frentes "estão relacionadas com as duas principais forças políticas que polarizam a disputa eleitoral neste país, mas ambas são associadas com propostas baseadas em fortes suspeitas em relação ao Estado”. (MARQUES, 2013, p. 10 [tradução da autora]).

Por um lado, a governança é pensada como sinônimo de eficiência estatal, com ênfase nas reformas do Estado e redefinição de suas funções, visando a práticas que resultariam em boa governança, em acepção fruto da escola de Administração Pública Gerencial. Na definição de Bresser-Pereira (1997), a governança do Estado é

sua capacidade de tornar efetivas as decisões do governo, através do ajuste fiscal, que devolve autonomia financeira ao Estado, da reforma administrativa rumo a uma administração pública gerencial (ao invés de burocrática), e a separação, dentro do Estado, ao nível das atividades exclusivas de Estado, entre a formulação de políticas públicas e a sua execução (BRESSER-PEREIRA, 1997, p.18).

Por outro lado, a governança é tratada na chave de processos participativos em políticas públicas, especialmente pela perspectiva da descentralização democrática (ABERS, 2010; ABERS et al., 2009), fortalecimento do poder local, bem como da democracia deliberativa (COELHO; FAVARETO, 2011) e do "impacto da sociedade civil sobre o desempenho de governos" 
(DAGNINO, 2002, p.282). As reflexões dessa perspectiva analítica podem ser condensadas na observação de Dagnino sobre as transformações do Estado brasileiro pós-redemocratização, como no trecho a seguir

Essas transformações no âmbito do Estado e da sociedade civil se expressam em novas relações entre eles: o antagonismo, o confronto e a oposição declarados que caracterizavam essas relações no período da resistência contra a ditadura perdem um espaço relativo substancial para uma postura de negociação que aposta na possibilidade de uma atuação conjunta, expressa paradigmaticamente na bandeira da 'participação da sociedade civil. (DAGNINO, 2002, p.13 - grifos do original).

A participação dos cidadãos na política sempre foi uma questão importante para a concepção de democracia. Contudo, é com o "significativo ressurgimento" da sociedade civil brasileira a partir dos anos 1970, fortalecido pelo processo de redemocratização no final da década de 1980, que se amplia e radicaliza a noção de democracia e cidadania no Brasil, bem como se fortalece a "necessidade de aprofundar o controle do Estado por parte da sociedade" e os "espaços de ampliação e democratização da gestão estatal" (cf. DAGNINO, 2002, p.10). E como resultado desse processo histórico de ampliação da democracia, experiências de participação social com incidência sobre as decisões políticas do Estado com base nas concepções de democracia direta, ou democracia participativa, ganharam força (SOUZA SANTOS; AVRITZER, 2003).

Apoiada nessa compreensão sobre a ampliação da democracia, as instituições participativas emergem no país com o intuito de difusão de inovações democráticas para o "exercício de diferentes graus de controle social democrático por cidadãos e organizações civis sobre as instituições políticas e as políticas públicas" (ISUNZA VERA; GURZA LAVALLE, 2012, p.107). A despeito da diversidade de dinâmicas participativas implantadas recentemente no Brasil, a ideia de inovação institucional e parceria entre Estado e sociedade pela incorporação de atores sociais em etapas de decisão e implementação em políticas públicas é o que conforma de modo geral o conjunto dessas experiências. Por esse motivo pode-se argumentar que a participação social em instâncias de participação é uma das formas possíveis de governança. 


\section{Literatura sobre participação social no Brasil}

As experiências de participação social no Brasil vêm se consolidando com ampliação crescente em paralelo ao progresso das análises feitas sobre elas. Após esforços de estudos sobre a participação social no Brasil terem focalizado as expectativas normativas sobre os atores da sociedade civil e em processos de democratização (AVRITZER, 1994; SOUSA SANTOS; AVRITZER, 2003), utilizando como estratégia metodológica olhar para experiências locais, o desafio atual do que se convencionou designar como a terceira geração de estudos sobre a sociedade civil (GURZA LAVALLE, 2011) tem sido desenvolver concepções mais abrangentes sobre essas experiências.

A definição de instituições participativas busca cumprir essa tarefa e foram definidas originalmente por Avritzer como "formas diferenciadas de incorporação de cidadãos e associações da sociedade civil na deliberação sobre políticas" (AVRITZER, 2008, p.45). Esse autor elabora a ideia de instituições participativas a partir da formulação de instituições pela teoria democrática como "conjunto de normas e de regras que estruturam a ação social e política” (AVRITZER, 2008, p.45). O argumento é que o conjunto de instituições participativas no Brasil não estão nem formal, nem legalmente constituídas, mas pautam comportamentos e expectativas dos atores sociais. Essa literatura tem se desenvolvido a partir da análise de experiências de institucionalização da participação social, e a conceituação do resultado desse processo como instituições participativas pode ser entendida como um primeiro passo na tentativa de agregação das múltiplas experiências em uma categoria mais ampla.

Dentre as instituições participativas ressaltadas pela literatura, foram inicialmente identificados os casos de Orçamento Participativo, de Conselhos de Políticas diversos e Planos Diretores (AVRITZER, 2008). Contudo, o surgimento de outros canais de interlocução entre Estado e sociedade recentemente com desenhos institucionais diversos tem crescido e ganhado importância nos estudos sobre o tema. Por esse motivo, outros arranjos foram sendo incorporados sob essa denominação, como é o caso de ouvidorias, pesquisas de avaliação de qualidade ou satisfação, conferências, entre outros (CORTES, 2011). No entanto, com a ampliação do uso da definição, sua própria designação passou a ser avaliada e reinventada. A definição de Cortes sobre as instituições participativas é de 
mecanismos de participação criados por lei, emendas constitucionais, resoluções ou normas administrativas governamentais que permitem o envolvimento regular e continuado de cidadãos com a administração pública, tanto diretamente quanto através de representantes, como ocorre com maior frequência. São instituições porque não se constituem em experiências episódicas ou eventuais de participação em projetos ou programas governamentais ou de organizações da sociedade civil ou do mercado. Ao contrário, estão instituídas como elementos característicos da gestão pública brasileira. (CORTES, 2011, p.137 - grifos da autora).

Percebe-se que essa redefinição é bem mais específica que a originalmente elaborada por Avritzer. A institucionalidade tratada é de tipo determinado e demarca o estabelecimento de continuidade na gestão pública do país. Essa conceituação explicitamente exclui experiências pontuais e volta o olhar para arranjos consolidados e perenes. A questão é que muitas experiências que incorporam a participação social nas políticas públicas não encontrariam espaço nessa chave, por não se encontrarem em tal estado de consolidação.

Como veremos adiante, este trabalho apresenta uma experiência de governança colaborativa que não se enquadra enquanto instituição permanente de gestão pública, mas cuja configuração compartilha características próprias da participação social em políticas públicas pela incorporação de atores sociais em etapas de decisão e implementação. Por isso vale destacar as variáveis da abordagem sobre a participação social no Brasil para compor o modelo teórico-metodológico de avaliação da efetividade proposto aqui.

Pode-se sublinhar em especial quatro aspectos principais utilizados para analisar a participação social no Brasil: (a) tipo de desenho institucional das experiências de participação; (b) organização da sociedade civil, ou seja, existência ou ausência de uma sociedade civil ativa e autônoma, em geral relacionada a certa tradição associativa; (c) vontade política, compreendida como iniciativa ou apoio de implementação de desenhos participativos nas políticas públicas por parte dos atores estatais; e (d) determinada cultura política, isto é, a existência ou não de características culturais diversas que podem ser mais associadas a concepções democráticas e participativas da realização das políticas (AVRITZER, 2008; CARLOS; SILVA, 2005; ROMÃO, 2010).

Essas quatro variáveis têm sido utilizadas por uma ampla parte dessa 
literatura como forma de avaliar as condições mais favoráveis para a participação social, bem como os melhores resultados que ela pode obter ${ }^{2}$.

No entanto, essa perspectiva tem deixado de compreender os processos que acontecem no interior das instituições participativas como processos políticos de gestão de políticas públicas. Romão (2010) defende que pensar os "espaços de participação como arenas políticas" permite voltar a atenção para os atores que estão nesses espaços bem como suas estratégias, por considerar a dinâmica interna dessas arenas permeadas pelos interesses políticos de cada um dos atores.

Ainda que a proposta deste trabalho não alcance as dinâmicas dos atores internas às arenas, o intuito é observar que as características estruturais de conformação dessas instâncias têm impacto sobre os seus resultados. Assim, acredita-se que as variáveis estruturais elencadas pela literatura de participação social podem ser utilizadas para pensar a efetividade dos fóruns de governança colaborativa.

\section{Literatura sobre gestão de bens comuns}

Como apresentado na introdução, a governança colaborativa, implementada pelo Programa Córrego Limpo da Sabesp, foi inspirada por um modelo desenvolvido a partir do trabalho de Mark Imperial (2005), autor que, por sua vez, tem por inspiração teórica a produção de Elinor Ostrom sobre a gestão de bens comuns. Os recursos ambientais, e em especial os cursos d'água, configuram-se como o exemplo ideal de bem comum, totalmente aderente ao modelo de Ostrom. Isso porque são um tipo de recurso que envolve diversos atores sociais em várias escalas e requer um tratamento comprometido entre os envolvidos com os resultados das decisões e ações tomadas conjuntamente (OSTROM, 2009).

Para Ostrom (2005, 2006), os bens comuns são produzidos pela ação coletiva através da interação coordenada entre os vários atores que dependem deles, no interior de instituições formuladas para garantir a gestão e desfrute

\footnotetext{
${ }^{2}$ Eventualmente, outros estudos podem não se restringir a essas variáveis. Porém, considerando os principais autores da literatura de participação social, em especial de instituições participativas, as variáveis aqui destacadas são as predominantes.
} 
desses bens através da cooperação ${ }^{3}$.

Tanto para Ostrom quanto para Imperial, a ação coletiva é implementada a partir de instituições, definidas como um conjunto de regras e normas elaboradas e aplicadas por um grupo de indivíduos para organizar suas ações. As regras e normas institucionalizadas incitam a cooperação entre os indivíduos, pois estabelecem confiança mútua levando à reciprocidade em suas ações e, por fim, à cooperação (OSTROM, 1998).

Assim, a ação coletiva é compreendida em relação direta com a cooperação, de modo diferente de como outros estudiosos clássicos do tema o delinearam. Essa autora constrói sua teoria em contraponto a Garret Hardin (1968) e Mancur Olson (1999), ambos pessimistas quanto às possibilidades de cooperação devido a análises pautadas pelos interesses individuais, sobretudo econômicos, e que oferecem duas alternativas coercitivas como contraponto à possibilidade da "tragédia dos bens comuns"”: via estatização ou privatização. A principal motivação do trabalho de Ostrom é reforçar a existência de uma terceira opção para resolver os problemas de ação coletiva: a gestão dos bens comuns pela sociedade.

Ela elabora essa ideia a partir de um modelo de autogoverno, pelo envolvimento dos atores afetados e agentes da política para a criação de uma gestão compartilhada, isto é, um "modelo em que os participantes estabelecem um contrato vinculante em que se comprometem com estratégias de cooperação que eles mesmos elaboraram" (Cf. MOURA, 2011, p.36). A ideia trabalhada pela autora é de self-governing institutions, instituições específicas para lidar com a gestão conjunta de recursos ambientais, que por definição são bens comuns (OSTROM, 2006). Assim, Ostrom desenvolve um poderoso modelo de análise das instituições criadas a partir da ação coletiva. O Institutional Analysis and Development Framework - IAD é um modelo analítico próprio para o estudo de gestão compartilhada, ação coletiva e recursos ambientais (KISER; OSTROM, 2000 [1982]).

\footnotetext{
${ }^{3}$ Veja que a concepção de que a ação coletiva se encaminha para a criação de instituições não é elaboração exclusiva de Ostrom. Boschi (1987) já afirma que a organização da ação coletiva tem imperativo organizacional dado pela necessidade de instrumentalização para a consecução de metas comuns, de modo que a "dimensão institucional é parte integrante da lógica da ação coletiva”. (BOSCHI, 1987, p.37).

${ }^{4}$ A "tragédia dos bens comuns" é uma formulação que simboliza a provável degradação do meio ambiente quando muitos indivíduos usam um bem escasso em comum, principalmente sem cuidados de renovação.
} 
A questão principal para a elaboração desse modelo analítico sobre os bens comuns é:

Como um grupo de dirigentes que se encontram em uma situação de interdependência podem se organizar para a obtenção de benefícios conjuntos contínuos frente a todas as tentações de freeriders, esquivar-se, ou agir de modo oportunista? [(OSTROM, 2006, p.29 - tradução da autora).

Complementarmente, as questões que se colocam nessas situações são: (a) como aumentar a probabilidade de iniciar a auto-organização?; (b) como aumentar as capacidades dos indivíduos para continuar os esforços auto-organizados ao longo do tempo?; e (c) como exceder a capacidade de auto-organização para resolver problemas de bens comuns sem nenhuma ajuda externa?

$\mathrm{Na}$ concepção de Ostrom, essas questões aparecem formuladas sob a perspectiva de dilemas sociais ${ }^{5}$ enfrentados na interação social entre diversos atores envolvidos em determinada ação coletiva. Contudo, a preocupação de fundo dessas questões é conduzir o estudo das condições observadas empiricamente que ajudam os atores a superar os problemas da autoorganização e de colaboração em suas ações para atingir os resultados esperados na gestão dos bens comuns. É interessante destacar que essas questões poderiam ser formuladas para pensar a efetividade nas experiências de participação social no Brasil e, por esse motivo, é possível comparar as duas abordagens e obter importantes elementos analíticos para a avaliação da efetividade.

E ainda que a teoria da ação coletiva com a qual Ostrom dialoga trabalhe com pressupostos bastante distintos dos que regem a abordagem participacionista, a formulação geral do tipo de instituição de ambas pode ser aproximada. Isso porque tanto Ostrom quanto a literatura de participação social remetem-se a estratégias amplas de governança que envolvem diferentes tipos de atores, tanto sociais quanto estatais, em atuação conjunta para o alcance de determinados resultados de políticas públicas. Para fins didáticos, os fóruns implementados pela Sabesp serão tratados como instâncias de

\footnotetext{
${ }^{5}$ Dilemas sociais dizem respeito à dificuldade de coordenação da ação de indivíduos em sua atuação conjunta e por isso base das reflexões sobre ação coletiva. Um dos exemplos clássicos de estudos sobre dilemas sociais é a tragédia dos comuns (HARDIN, 1868).
} 
participação social apenas devido ao histórico de difusão desse tipo de experiência no Brasil, sem significado de prevalência de uma abordagem sobre outra nesse quesito. No entanto, apesar de Ostrom dialogar com a teoria da ação coletiva, ela avança com a proposição de se considerarem diversas arenas e níveis de análise onde operam os atores.

Dentre os níveis analíticos propostos por Ostrom, a unidade de investigação do IAD é a rede política ou arena de ação (SILVA FILHO et al., 2009). Essa arena de ação é o lugar das escolhas e decisões sociais, e é essa arena, as situações de ação e os atores envolvidos nela os focos privilegiados da análise de Ostrom (UNIVERSITY OF COLORADO, s/d). A chave para a compreensão desse modelo analítico é entender como os atributos individuais e internos do grupo de atores envolvidos ${ }^{6}$ se combinam com variáveis estruturais em determinada situação de provisão e apropriação de um bem comum.

Segundo o IAD, as variáveis estruturais que influenciam a arena de ação são três: (a) as instituições ou regras que ordenam as relações entre os atores; (b) os atributos das comunidades onde os atores estão inseridos; e (c) os atributos do ambiente físico onde a comunidade atua (OSTROM, 1999; 2005).

Pode-se compreender que a rede política ou arena de ação de Ostrom é a composta pelos atores envolvidos em determinada ação coletiva e, consequentemente, na instituição criada para lidar com a gestão de bens coletivos. Como a abordagem de Ostrom influenciou o modelo de constituição dos fóruns de governança colaborativa da Sabesp, esses fóruns foram criados especificamente com o intuito de preservação dos córregos limpos. De modo que a institucionalidade dos fóruns pode ser compreendida como a arena de ação privilegiada para a gestão desses cursos d'água. Como essas variáveis podem ser comparadas com a abordagem de participação social será apresentado na próxima sessão.

\footnotetext{
${ }^{6}$ Esses atributos são tamanho do grupo, heterogeneidade dos participantes, sua dependência sobre os benefícios recebidos, as taxas de desconto, o tipo de previsão dos processos de transformação envolvidos, envolvimento dos níveis organizacionais, técnicas de monitoramento e informações disponíveis aos participantes (OSTROM 1997, apud MOURA, 2011). Contudo, eles não serão analisados no momento por fugirem ao escopo deste trabalho.
} 


\section{Combinação dos modelos nos fóruns de governança colaborativa}

Na comparação entre a literatura que lida com a participação social no Brasil e a abordagem de Ostrom, percebe-se que é possível contrastar as variáveis estruturais de ambas as perspectivas. Isto é, as variáveis que influenciam a arena de ação podem ser contrapostas às variáveis utilizadas na literatura de participação brasileira, pois ambos os conjuntos de variáveis operam com características estruturais que incidem sobre instâncias de participação social. Resumidamente, podemos comparar as duas abordagens, conforme o quadro 1, cuja terceira coluna apresenta a síntese da combinação.

\begin{tabular}{|c|c|c|}
\hline $\begin{array}{c}\text { Literatura de } \\
\text { participação social }\end{array}$ & $\begin{array}{c}\text { Literatura de gestão de } \\
\text { bens comuns }\end{array}$ & Síntese \\
\hline Desenho Institucional & Instituições ou regras & Desenho Institucional \\
\hline $\begin{array}{c}\text { Organização da } \\
\text { Sociedade Civil }\end{array}$ & $\begin{array}{c}\text { Atributos da } \\
\text { comunidade }\end{array}$ & $\begin{array}{c}\text { Características dos } \\
\text { atores sociais }\end{array}$ \\
\cline { 1 - 1 } Vontade Política & Atributos do ambiente \\
fúsico & $\begin{array}{c}\text { Atributos do ambiente } \\
\text { físico }\end{array}$ \\
\hline $\mathrm{X}$ & \begin{tabular}{c} 
Cultura Política \\
\hline
\end{tabular}
\end{tabular}

Quadro 1 - Comparação das duas abordagens

Fonte: Elaborado pela autora a partir de análise da bibliografia.

Nesse nível de agregação, fica visível como as características utilizadas para pensar as instâncias de participação estabelecem paralelos entre as literaturas. Nos próximos itens são feitas comparações entre cada uma das variáveis dessas literaturas, juntamente com a análise do caso empírico.

Os dados empíricos dizem respeito às cinco bacias selecionadas para participarem do projeto-piloto de implementação dos fóruns de governança colaborativa pela Sabesp dentre as participantes do Programa Córrego Limpo. O ponto de partida dos fóruns foi o diagnóstico das redes de lideranças e o conhecimento da existência ou ausência de mobilização prévia a respeito do córrego. Esses fóruns foram implementados durante três meses, entre maio 
e julho de $2010^{7}$, a partir do convite à população e lideranças mapeadas em pesquisa anterior realizada nas comunidades do entorno (GUARNIERI $e t$ al., 2009).

\section{V.a. Desenho institucional}

A primeira das variáveis a ser analisada diz respeito ao desenho institucional dos fóruns de governança colaborativa implementados pela Sabesp. Como vimos na literatura de participação social, esse desenho institucional pode ser entendido de modo amplo como o formato final de funcionamento da instância participativa que se estuda.

No caso da abordagem de Ostrom, a primeira variável que influencia a arena de ação são as instituições formadas por um "conjunto de regras em uso" e todas as regras contêm preceitos que proíbem, permitem ou requerem alguma ação ou resultado.

'Instituições' podem ser definidas como conjuntos de regras em uso para determinar quem é elegível para tomar as decisões em determinada arena, quais ações são permitidas ou constrangidas, quais regras de agregação serão usadas, quais procedimentos devem ser seguidos, quais informações devem ou não ser fornecidas, e quais recompensas serão atribuídas aos indivíduos por suas ações. [(OSTROM, 2006, p.51 - tradução da autora].

Em resumo, as regras em uso são de conhecimento comum e sempre monitoradas e executadas pelos atores diretamente envolvidos. De modo que todos os participantes estão informados sobre as regras e sabem que os demais também estão, constituindo um relacionamento de reciprocidade e colaboração no comportamento dos indivíduos.

No caso dos fóruns, a Sabesp teve a iniciativa de sua criação, com um desenho institucional bastante semelhante entre eles. Isto é, a Sabesp fez

\footnotetext{
${ }^{7}$ Período de acompanhamento dos fóruns pela equipe de assessoria do Cem/Cebrap. Alguns fóruns permaneceram após esse período, e o fórum do córrego Itupu foi criado posteriormente (GUARNIERI et al, 2010). As fontes de dados empíricos utilizadas foram, principalmente, os relatórios da assessoria do Cem/Cebrap (GUARNIERI et al, 2009; 2010), atas das reuniões e outros documentos elaborados pelos participantes dos fóruns, como seus Regimentos Internos e outros. Algumas entrevistas com as lideranças da comunidade bem com representantes da Sabesp também foram fonte de consulta.
} 
um conjunto de regras iguais para todos os projetos ${ }^{8}$ e fóruns, o que poderia significar pouca variação entre os casos. E, no sentido de Avritzer (2008), poder-se-ia dizer se tratar de um desenho institucional "de baixo para cima", tendendo a operar por ratificação e com pouco potencial participativo. Contudo, outras regras foram criadas para os regimentos internos de cada fórum, compondo um conjunto de regras em uso, no sentido de Ostrom (2006), compartilhadas pelos participantes. O quadro 2 mostra a variação dentre os cinco casos.

\begin{tabular}{|c|c|c|c|c|c|}
\hline Características & $\begin{array}{c}\text { Charles de } \\
\text { Gaulle }\end{array}$ & Cipoaba & $\begin{array}{c}\text { Cruzeiro do } \\
\text { Sul }\end{array}$ & Ibiraporã & Itupu \\
\hline $\begin{array}{c}\text { institucional } \\
\text { Fórum } \\
\text { específico }\end{array}$ & $\begin{array}{c}\text { Incorporação } \\
\text { do fórum ao } \\
\text { movimento } \\
\text { preexistente }\end{array}$ & $\begin{array}{c}\text { Fórum } \\
\text { específico }\end{array}$ & $\begin{array}{c}\text { Fórum } \\
\text { específico }\end{array}$ & $\begin{array}{c}\text { Fórum com } \\
\text { dificuldades de } \\
\text { implementação }\end{array}$ \\
\hline $\begin{array}{c}\text { Regras para } \\
\text { funcionamento } \\
\text { do fórum }\end{array}$ & $\begin{array}{c}\text { Representação } \\
\text { e votação }\end{array}$ & Consenso & $\begin{array}{c}\text { Representação } \\
\text { e votação }\end{array}$ & $\begin{array}{c}\text { Representação } \\
\text { e votação }\end{array}$ & Não se aplica \\
\hline
\end{tabular}

Quadro 2 - Desenho institucional

Fonte: Elaborado pela autora com base em GUARNIERI et al. (2009; 2010).

Os participantes criaram regimentos próprios bem como moldaram o formato dos fóruns, de acordo com suas especificidades locais. Isso produziu uma variação entre formatos de deliberação e de modelo institucional adotados em cada região. Como primeiro exemplo, cito o caso do fórum do córrego Cipoaba. É digno de nota a atuação do Movimento pela Revitalização do Córrego Cipoaba desde 2004, articulado, principalmente, por professores e alunos de uma escola estadual, localizada próxima às margens do córrego. Esse movimento uniu esforços com a consolidação do fórum, que foi incorporado às reuniões já existentes do movimento. Assim, alguns ajustes foram feitos com relação à periodicidade das reuniões para acomodar as necessidades do fórum, mas não se abriu mão do método de tomada de decisões por consenso, próprio ao movimento. Esse foi o único fórum que optou pelo método do consenso para a tomada de decisões, enquanto os demais definiram a representação e a votação.

\footnotetext{
${ }^{8}$ Os projetos a serem elaborados pelos fóruns receberam patrocínio financeiro da Sabesp e, para tanto, precisavam se adequar às regras próprias de financiamento da companhia. Entre essas regras estavam a exigência de uma instituição formalizada responsável pelo projeto e a proibição de compra de material permanente.
} 
Na região do córrego Cruzeiro do Sul existiam muitos outros fóruns com dinâmicas próprias na comunidade, mas, nesse caso, seus participantes decidiram pela criação de um fórum específico para não interferir nos já existentes. Contudo, chama a atenção o fato de o córrego ser cortado por uma rodovia ao longo de sua extensão, dividindo a comunidade em duas áreas distintas. Na análise dos documentos gerados por esse fórum, essa questão é constantemente marcada, valendo a citação de trecho de seu regimento:

Dadas as diferenças demográficas, define-se que este fórum seja composto por duas lideranças titulares moradoras da parte de cima do córrego e três lideranças titulares da parte de baixo do córrego. (...) Para referendar as decisões do fórum é necessária a presença de pelo menos um representante de cada uma das partes do córrego. (Regimento do fórum Cruzeiro do Sul).

Aqui temos a demonstração de como as especificidades locais, no caso envolvendo questões territoriais, tiveram influência sobre as regras de composição do regimento do fórum. Adiante será discutido o impacto que isso teve sobre o resultado final. Por ora vale mencionar que foi o único fórum no qual as regras e comportamento dos participantes incentivavam a elaboração de mais de um projeto.

Os fóruns dos córregos Charles de Gaulle e Ibiraporã não diferem entre si quanto as características do desenho institucional analisadas aqui: ambos foram criados como instituições específicas e decidiram pela representação e votação como método de tomada de decisões.

Já o fórum do córrego Itupu enfrentou muitas dificuldades para sua implementação no mesmo período que os demais. Essas dificuldades serão analisadas em conjunto com as características discutidas a seguir.

\section{V.b. Características dos atores sociais}

Quanto à análise dos atores sociais locais, o primeiro elemento importante para a literatura de participação social é a organização da sociedade civil. Existem estudos que tratam do histórico de tradição associativa em bairros de São Paulo e, de acordo com essa bibliografia, a zona leste da cidade se destacaria por seu histórico de formação de movimentos sociais ligados a entidades religiosas e ao setor de saúde do município (COELHO et al., 2010; IFFLY, 2010). Dentre as áreas onde foram criados os fóruns, duas se 
encontram na zona leste: o córrego Cruzeiro do Sul e o córrego Cipoaba. Além da participação de representantes de movimentos sociais nesses dois fóruns, no caso do córrego Cipoaba, notamos a presença de um movimento social que atuava em prol da despoluição desse córrego, antes mesmo da existência do fórum. E, apenas nesses dois casos, a rede de lideranças convidada a participar do fórum era bastante consolidada, antes mesmo da implementação dele, como veremos no quadro 3 .

\begin{tabular}{|c|c|c|c|c|c|}
\hline Características & $\begin{array}{c}\text { Charles de } \\
\text { Gaulle }\end{array}$ & Cipoaba & Cruzeiro do Sul & Ibiraporã & Itupu \\
\hline Rede de lideranças & $\begin{array}{c}\text { Rede } \\
\text { dispersa - } \\
\text { convite a } \\
\text { novos atores }\end{array}$ & $\begin{array}{c}\text { Rede consolidada } \\
\text { - fórum negociado } \\
\text { com as lideranças } \\
\text { locais }\end{array}$ & \begin{tabular}{|} 
Rede consolidada \\
fórum negociado \\
com as lideranças \\
locais
\end{tabular} & $\begin{array}{c}\text { Rede dispersa - } \\
\text { convite a novos } \\
\text { atores }\end{array}$ & $\begin{array}{c}\text { Rede dispersa - } \\
\text { convite a novos } \\
\text { atores }\end{array}$ \\
\hline $\begin{array}{c}\text { Número de } \\
\text { lideranças na rede }\end{array}$ & Alto & Baixo & Alto & Baixo & Baixo \\
\hline Densidade da rede & Baixa & Alta & Média & Média & Baixa \\
\hline $\begin{array}{l}\text { Estimativa de } \\
\text { população na } \\
\text { bacia }(2000)\end{array}$ & 5.785 & 48.032 & 29.081 & 4.256 & 37.145 \\
\hline $\begin{array}{c}\text { Condições } \\
\text { socioeconômicas* }\end{array}$ & $\begin{array}{c}\text { Áreas não } \\
\text { vulneráveis à } \\
\text { pobreza }\end{array}$ & $\begin{array}{c}\text { Heterogeneidade, } \\
\text { abrigando } \\
\text { populações pobres } \\
\text { e classe média- } \\
\text { baixa }\end{array}$ & $\begin{array}{c}\text { Heterogeneidade, } \\
\text { abrigando } \\
\text { populações } \\
\text { pobres e classe } \\
\text { média-baixa }\end{array}$ & $\begin{array}{c}\text { Homogeneidade, } \\
\text { abrigando } \\
\text { população de } \\
\text { classe média e } \\
\text { média alta }\end{array}$ & $\begin{array}{l}\text { Heterogeneidade, } \\
\text { abrigando } \\
\text { populações pobres } \\
\text { e classe média- } \\
\text { baixa }\end{array}$ \\
\hline $\begin{array}{c}\text { Áreas vulneráveis à } \\
\text { pobreza* }\end{array}$ & $\begin{array}{c}0 \% \text { dos } \\
\text { domicílios }\end{array}$ & $\begin{array}{l}\text { 10,4\% dos } \\
\text { domicílios }\end{array}$ & $\begin{array}{l}54,9 \% \text { dos } \\
\text { domicílios }\end{array}$ & $\begin{array}{c}0 \% \text { dos } \\
\text { domicílios }\end{array}$ & $\begin{array}{c}42 \% \text { dos } \\
\text { domicílios }\end{array}$ \\
\hline
\end{tabular}

Quadro 3-Atores sociais

Fonte: Elaborado pela autora com base em GUARNIERI et al. (2009; 2010).

* Condições socioeconômicas calculadas com base no Índice Paulista de Vulnerabilidade Social - IPVS - da fundação SEADE, adaptadas para áreas de bacias hidrográficas.

Dentre as características dos atores sociais, podemos identificar as diferentes formas de articulação prévia das lideranças a partir da análise de suas redes em cada bacia. Por exemplo, no córrego Cipoaba existia um consolidado movimento preocupado com a conservação do córrego, inclusive com participação ativa na proposição de projetos junto à subprefeitura de São Mateus e bem informado sobre o Programa Córrego Limpo. Parte das pessoas desse movimento foi identificada na rede de lideranças, que era uma rede densa, isto é, uma rede na qual a maioria das pessoas presentes tem contatos entre si. Por conta dessa conjuntura, foi decidido incorporar a 
proposta do fórum de governança colaborativa da Sabesp às reuniões desse movimento, de modo a unir forças e otimizar as discussões e decisões, como vimos anteriormente.

Já no córrego Cruzeiro do Sul, a rede identificada indicava uma ampla gama de lideranças com algumas ligações entre elas, mas com uma densidade média. Tanto nas entrevistas realizadas quanto na primeira reunião de proposição do fórum, foi constatada a existência de diversas instâncias de articulação da comunidade, como outros fóruns e reuniões com interesses diversos, demonstrando a intensa organização da sociedade civil e sua tradição associativa.

No caso do córrego Ibiraporã, além de a rede de lideranças ser pequena, com poucas lideranças, ela ainda era centralizada na figura do presidente da Associação de Moradores da Rua Ibiraporã - AMRI. Inclusive, foi ele quem solicitou a inclusão do córrego no Programa Córrego Limpo da Sabesp. Além da proeminência dessa associação, uma parte considerável dos participantes desse fórum era da Sociedade Amigos de Bairro de Vila Suzana - SABVL e da Sociedade Amigos do Morumbi e Vila Suzana - SAMOVIS. De modo que nesse fórum foi marcante a presença de associações locais com perfil territorial, e sem presença de pessoas relacionadas a qualquer movimento social ou ONG. De fato, notou-se que a comunidade não é mobilizada em outros tipos de associações ou fóruns locais.

De acordo com estudo que traça o perfil das associações civis, as associações de moradores ou de amigos de bairro são conectadas a um perfil socioeconômico de classe média no Brasil (GURZA LAVALLE; CASTELO; BICHIR, 2006). E elas costumam fazer demandas específicas de melhorias urbanas distintas de associações de bairros populares - geralmente tratadas apenas como associações de bairro. Nesse sentido, podemos notar que a tradição associativa da comunidade do córrego Ibiraporã é do primeiro tipo.

No córrego Charles de Gaulle, a rede tinha um número alto de lideranças, mas com densidade baixa, pois muitas não atuavam em conjunto. Por esse motivo foram feitos convites a novos participantes.

Como último exemplo, cito o caso do córrego Itupu. Nesta bacia, a rede indicava poucas lideranças e baixo nível de relação entre elas, o que apontava para a necessidade de um trabalho inicial de articulação e/ou fomento de novas lideranças. Nessa região, foram identificadas poucas lideranças, e uma das razões citadas pelos entrevistados era o fato de serem bairros de ocupação recente e com dificuldade de articulação entre os moradores. Mas o grande 
número de moradores na bacia também foi aventado pela Sabesp como um motivo adicional da dificuldade de mobilização para o fórum.

De acordo com Ostrom (2006), a quantidade de pessoas que fazem uso de determinado recurso é um dos fatores a ser considerado como parte dos atributos da comunidade e que tem influência sobre a arena de ação. Em geral, quanto maior o número de pessoas envolvidas, mais difícil pode ser sua coordenação para atingir o resultado esperado. Por esse motivo, a quarta linha do quadro 3 apresenta a estimativa da população na área da bacia de cada córrego.

Se compararmos a estimativa de população na bacia com suas redes de lideranças, podemos observar que o Itupu conta com uma população bem numerosa, mas com uma rede com poucas lideranças, pouco densa e dispersa. Já a bacia do córrego Cipoaba, a mais numerosa dos cinco casos, também tinha um baixo número de lideranças, mas sua rede era densa e consolidada e, além disso, contava com a existência de um movimento específico em prol do córrego. A bacia do Cruzeiro do Sul, a terceira maior em número de estimativa de população, contava com uma rede consolidada, com grande número de lideranças, apesar da baixa densidade de contatos entre elas. $\mathrm{E}$ as bacias dos córregos Charles de Gaulle e Ibiraporã não apresentavam os melhores indicadores sobre as redes de lideranças, sendo ambas redes dispersas, e as menores em termos populacionais.

Assim, podemos concluir que o número de moradores da bacia pode não ser um fator isolado de atuação sobre o resultado do fórum, mas que, analisado em conjunto com a organização da sociedade civil, mostra combinações mais ou menos favoráveis para o funcionamento e resultado dos fóruns.

Os dois últimos aspectos analisados sobre os atores sociais no quadro dizem respeito às condições socioeconômicas da população, em especial em relação a vulnerabilidade social à pobreza. Nota-se que as duas menores bacias em termos populacionais, Charles de Gaulle e Ibiraporã, não possuem população vulnerável, enquanto as demais áreas possuem. Esse aspecto será discutido a seguir, combinado com os atributos do ambiente físico ${ }^{9}$.

\footnotetext{
9 Apesar das variáveis cultura e vontade política também poderem ser analisadas como características dos atores sociais, acredita-se que essas variáveis necessitam de uma abordagem mais aprofundada e crítica, que foge ao escopo deste trabalho. Por ora apenas é indicada sua relevância na literatura de participação social brasileira, a possibilidade de comparação com o quadro teórico-metodológico de Ostrom e da síntese comparativa aqui proposta entre essas bibliografias.
} 


\section{V.c. Atributos do ambiente físico}

Podemos dizer que a literatura de participação social recorrentemente reconhece a variação de contexto como importante fator sobre os resultados da participação. No entanto, a ideia de contexto se relaciona invariavelmente a dinâmicas sociais e políticas, principalmente em termos associativos ou de mobilização social, o que poderia ser enquadrado como atributos da comunidade para Elinor Ostrom. Apenas essa autora reconhece as características físicas do local de atuação da comunidade como variável importante de incidência sobre a arena de ação.

Os córregos eleitos para participar do projeto-piloto de implementação dos fóruns da Sabesp seguiram critérios que tinham por objetivo abarcar a diversidade de contextos de implementação dos fóruns no futuro ${ }^{10}$, possibilitando uma avaliação inicial da política, para aprimoramento para as comunidades seguintes. A variabilidade observada diz respeito à região da cidade, distribuída pelos bairros atendidos pelas cinco Unidades de Negócio $^{11}$ da Sabesp. Mas a localização nas diferentes áreas da cidade pode ser mais bem compreendida se analisada em conjunto com outros aspectos do ambiente físico, como as construções habitacionais. E, de certo modo, podemos observar que as construções habitacionais (quadro 4) estão associadas às condições socioeconômicas do entorno dos córregos, já exploradas no quadro 3 .

\footnotetext{
${ }^{10}$ Por se tratar de projeto-piloto, os cinco fóruns implementados foram criados com a intenção de servir de teste para a reprodução futura do modelo nos outros córregos participantes do programa.

${ }^{11}$ As Unidades de Negócio - UN da Sabesp são unidades administrativas com delimitada área de atuação definida de acordo com as cinco zonas da cidade. A exceção é a UN Centro, que abarca uma parte do território da Zona Leste e, por esse motivo, o córrego selecionado nessa unidade fica situado nessa zona, em São Mateus.
} 


\begin{tabular}{|c|c|c|c|c|c|}
\hline Características & $\begin{array}{c}\text { Charles de } \\
\text { Gaulle }\end{array}$ & Cipoaba & $\begin{array}{l}\text { Cruzeiro do } \\
\text { Sul }\end{array}$ & Ibiraporã & Itupu \\
\hline Zona da Cidade & Norte & Leste & Leste & Oeste & Sul \\
\hline Bairro & $\begin{array}{c}\text { Parque São } \\
\text { Domingos }\end{array}$ & São Mateus & $\begin{array}{l}\text { Vila Santa } \\
\text { Inês }\end{array}$ & Vila Sônia & $\begin{array}{c}\text { Jardim } \\
\text { Ângela, } \\
\text { Copacabana } \\
\text { e Jardim } \\
\text { Kagohara }\end{array}$ \\
\hline $\begin{array}{l}\text { Construções } \\
\text { habitacionais }\end{array}$ & $\begin{array}{c}\text { Área } \\
\text { consolidada }\end{array}$ & Área mista & $\begin{array}{c}\text { Área em } \\
\text { consolidação }\end{array}$ & $\begin{array}{c}\text { Área } \\
\text { consolidada }\end{array}$ & Área instável \\
\hline $\begin{array}{l}\text { Local de } \\
\text { reunião }\end{array}$ & $\begin{array}{c}\text { Parque } \\
\text { Municipal } \\
\text { Jardim São } \\
\text { Domingos }\end{array}$ & $\begin{array}{l}\text { Igreja e } \\
\text { depois } \\
\text { escola } \\
\text { pública }\end{array}$ & $\begin{array}{c}\text { Vários } \\
\text { locais: escola } \\
\text { pública, } \\
\text { CDHU } \\
\text { e uma } \\
\text { instituição de } \\
\text { um pastor e } \\
\text { uma de um } \\
\text { padre }\end{array}$ & $\begin{array}{c}\text { Escola } \\
\text { particular } \\
\text { e sede da } \\
\text { Caritas }\end{array}$ & $\begin{array}{c}1 \text { reunião } \\
\text { no Parque } \\
\text { estadual da } \\
\text { Guarapiranga }\end{array}$ \\
\hline
\end{tabular}

Quadro 4-Atributos do ambiente físico

Fonte: Elaborado pela autora com base em GUARNIERI et al. (2009; 2010).

Mais uma vez, a área do córrego Charles de Gaulle e Ibiraporã apresentam características similares quanto às suas construções habitacionais: são bairros consideravelmente consolidados. De fato, essa informação poderia mesmo ser esperada de locais sem vulnerabilidade social e com população de classe média e média alta.

Já os córregos Cipoaba, Cruzeiro do Sul e Itupu se localizam em áreas de maior heterogeneidade social, com populações pobres e de classe médiabaixa e com índices de vulnerabilidade que chegam até a 54,9\%, no caso do Cruzeiro do Sul. Nesses casos, as condições habitacionais divergem. A região do córrego Cipoaba foi denominada mista, por apresentar uma parte de casas consolidadas, mas também algumas áreas de ocupações irregulares.

O entorno do córrego Cruzeiro do Sul é uma região onde estão sendo feitos inúmeros conjuntos habitacionais. No período de implementação dos fóruns, as duas regiões separadas pela rodovia que corta o córrego estavam em diferentes estágios de atendimento pelos programas habitacionais. $\mathrm{Na}$ considerada "parte de cima", mais alta, já tinham sido concluídas as obras habitacionais e também das margens do córrego, incluindo a construção de parque linear, com equipamentos públicos de lazer. Mas a outra parte ainda estava em obras, inclusive com entulhos e maquinaria de construção civil, 
além de muitas habitações irregulares e em condições precárias.

Por fim, as condições habitacionais da região do córrego Itupu eram as mais incertas. Não apenas pelo fato de ser uma região com muitas ocupações irregulares e recentes, incluindo as áreas de córrego e mananciais, mas também porque essa situação deixava a população em constante preocupação com as possibilidades de despejo ou remoção ${ }^{12}$. Algumas pessoas que participaram da única reunião do fórum chegaram a afirmar que estavam lá com o intuito de ter informações sobre as desapropriações que estavam acontecendo na região, pois essa era a preocupação mais urgente dos moradores.

Interessante notar que os locais de reunião do fórum variaram entre escolas, parques e instituições religiosas. Esses locais geralmente tinham representantes nos fóruns, como o caso da escola pública utilizada pelo Cipoaba, que era a mesma de origem do movimento, e, no caso do Charles de Gaulle e Itupu, por representantes de instituições públicas que atuavam nos parques. Mas chama a atenção o fato de o Ibiraporã ser o único dos fóruns que utilizou como sede também uma escola particular, a única instituição privada dos casos. Também se destaca o rodízio de locais de reuniões proposto pelos participantes do fórum do Cruzeiro do Sul como forma de contemplar as várias lideranças, as duas áreas do entorno, bem como as duas religiões com líderes bastante atuantes.

\section{Efetividade dos fóruns de governança colaborativa da Sabesp}

$\mathrm{Na}$ trajetória da literatura sobre espaços de participação social no Brasil, é interessante observar que o debate sobre efetividade das instituições participativas é uma das principais agendas de pesquisa atual sobre a participação social. E esse debate está justamente concentrado nos efeitos das instituições participativas e sua relação com as políticas públicas ${ }^{13}$.

Contudo, ainda que o debate sobre a efetividade das instituições participativas tenha se consolidado recentemente, essa preocupação pode ser

\footnotetext{
${ }^{12}$ De fato durante o convite para as lideranças participarem do fórum, elas afirmaram que 70 casas foram demolidas pela subprefeitura.

13 A relevância desse enfoque tem sido diagnosticada pela literatura, e o título do volume "Efetividade das instituições participativas no Brasil: estratégias de avaliação" (PIRES, 2011) é significativo sobre esse empreendimento.
} 
notada mesmo em trabalhos anteriores que não explicitam essa preocupação. Isso porque muitos estudos sobre o tema da participação buscaram analisar suas instâncias a partir dos resultados alcançados em termos de desenvolvimento da democracia (SOUSA SANTOS; AVRITZER, 2003). São trabalhos que se estruturaram a partir da análise da democratização envolvida em uma ou outra experiência de participação social. Ainda que o debate não se apoiasse em metodologias e variáveis de mensuração de resultados, o horizonte da "viabilidade da gestão participativa plena" (ABERS et al., 2009) ou da democratização da democracia (SOUSA SANTOS; AVRITZER, 2003) estava sempre presente e forjava o grau de aferição da experiência em estudo.

De fato, uma das novidades nos estudos da efetividade da participação tem sido o reconhecimento da variedade de resultados possíveis dentre a diversidade de experiências participativas. A questão é que a avaliação de resultados tem tomado contornos diferenciados e se consolida a ideia de que as experiências são diversas e os resultados alcançados também. De modo que a variabilidade das modalidades de participação não necessariamente pode ser avaliada num mesmo modelo, nem formular efeitos iguais ou semelhantes - há que se analisar os diferentes casos empiricamente e, mais que isso, definir qual tipo de resultado está em foco.

Atualmente, o debate se desenrola em torno de uma variedade de propósitos e metodologias para entender a efetividade das experiências participativas. Isso porque a literatura sobre o tema recai sobre diferentes formas de pensar a efetividade, sendo que a mais recorrente ainda procura estabelecer relações diretas entre a participação específica em instituições e resultados democratizantes mais amplos sobre o sistema social e político como um todo.

Contudo, estudos mais críticos apontam distinções necessárias para se avaliar os efeitos da participação. Gurza Lavalle (2011) defende a necessidade de fugir da "tentação da causalidade remota" ${ }^{4}$. Uma de suas recomendações seria aproximar causa e efeito, voltando o olhar para os "efeitos imediatos ou diretamente imputáveis às IPs [instituições participativas] naquilo que efetivamente produzem" (GURZA LAVALLE, 2011, p.41).

\footnotetext{
14 "Uma causalidade remota é aquela em que a relação entre causa e efeito é atravessada por espaço longo de tempo e/ou mediada por uma sucessão ou encadeamento extenso de efeitos intermediários. Por que evitar causalidades remotas? Quanto mais distante for a causa do efeito, mais difícil é mostrar que existe uma conexão." (GURZA LAVALLE, 2011, p.41).
} 
De fato, seria possível pensar em algumas opções de resultados dos fóruns. Uma primeira escolha poderia recair sobre o modo como ocorre o envolvimento dos atores sociais nesses fóruns, dada a variabilidade do comportamento, intencionalidade e disponibilidade dos atores. Outra opção poderia ser a avaliação do método de funcionamento dos fóruns a partir dos modelos institucionais elaborados, por exemplo, se as deliberações são encaminhadas por consenso ou por votação e como acontece esse processo. Essas duas opções seriam formas de avaliar a efetividade da participação em si. E paralelamente a elas, poder-se-ia pensar sobre a continuidade do fórum como forma de mensurar o sucesso do desenho institucional.

No entanto, se pensarmos nos objetivos da política de saneamento dentro do Programa Córrego Limpo, também seria possível apreender os resultados, tanto a partir da elaboração dos projetos quanto pela implementação destes e, até mesmo, pela perenização da despoluição dos córregos, objetivo final do programa. Por fim, seria possível até mesmo pensar em combinações ou em avaliações paralelas de resultados como forma de abarcar toda a experiência participativa desenvolvida no interior dos fóruns de governança em questão. A existência de tantas opções de avaliação da efetividade em apenas um caso de estudo mostra a complexidade da tarefa.

A decisão para o presente trabalho foi se deter propriamente no objetivo direto da implementação dos fóruns, qual seja, a elaboração de projetos para a preservação da limpeza dos córregos. Ainda que o conteúdo dos projetos tenha tido um núcleo comum de propostas educativas para os moradores das regiões, bem como a valorização de experiências locais de atuação na preservação, é interessante observar os pontos específicos de cada um deles.

Os dois casos que tiveram projetos elaborados, sem maiores distinções, foram os fóruns dos córregos Charles de Gaulle e Ibiraporã. O desenho institucional desses fóruns foi o mesmo e, apesar de estarem em diferentes zonas da cidade, suas condições socioeconômicas são as melhores do grupo, e a composição geral das redes de liderança indica dispersão e necessidade de convocar novos atores para os fóruns. É interessante notar que apenas nesses dois casos algumas atividades dos fóruns bem como os projetos propostos envolveram preocupações acerca de questões de segurança e uso de câmeras de vigilância nas casas ou ruas, colocação de placas e lixeiras ${ }^{15}$. De fato,

\footnotetext{
${ }^{15}$ Ainda que fosse probida a compra de material permanente pelas regras de financiamento da Sabesp, foram feitas discussões para inserir a compra das câmeras de vigilância nos projetos.
} 
ainda que questões de fiscalização e denúncia das ações de poluição fossem discutidas em outros fóruns, esses dois foram os únicos que apresentaram propostas formais nesse sentido. No caso do córrego Cipoaba, temos o já citado Movimento pela Revitalização do Córrego Cipoaba, que uniu esforços com a consolidação do fórum e avançou em algumas de suas demandas anteriores na elaboração de seu projeto. É possível argumentar que esse resultado teve relação com as regras de funcionamento do fórum formuladas em consonância com a dinâmica preexistente e também se relaciona com os atributos da comunidade, uma vez que a rede consolidada remete diretamente ao movimento. De fato, a existência do movimento ligado ao córrego pode ter sido decisiva para contrabalançar a tendência desvantajosa do grande número de moradores na bacia do córrego Cipoaba.

O projeto elaborado por esse fórum tinha três objetivos: (a) capacitação dos jovens para a elaboração de canais de comunicação e divulgação sobre o projeto de revitalização existente desde 2004; (b) educação ambiental; (c) eventos para divulgação do trabalho e envolvimento da comunidade. A análise do projeto mostra que seu eixo era a divulgação e expansão de ações que estavam em andamento pelo movimento em prol do córrego, em especial a atuação junto aos professores, funcionários e alunos da escola que foi sede de suas reuniões. O caso do fórum do córrego Cruzeiro do Sul apresenta semelhanças com o anterior quanto à composição geral da rede e as características socioeconômicas de sua população. No entanto, o modelo institucional escolhido foi diferente, com o estabelecimento de um fórum específico para evitar competição de temática com outros fóruns existentes na região. Também foi feito um revezamento entre os locais de reunião para poder atender às variadas lideranças e instituições interessadas. Apesar de sua população ser também bastante numerosa e em condições socioeconômicas de vulnerabilidade à pobreza, o fator recorrentemente mencionado para a formulação das regras do fórum era a questão das "diferenças demográficas" dos dois lados do córrego, dado pelo corte feito por uma rodovia em sua extensão. Esse atributo do ambiente físico teve influência tanto sobre o desenho institucional quanto pelas características dos atores sociais. Contudo, sua maior incidência pode ser observada sobre o resultado final dos fóruns: foi o único cujos participantes decidiram fazer dois projetos.

Um dos projetos era de mobilização de público infantil, e envolvia caminhadas pelo córrego, panelaço de conscientização ambiental na região e fotografias com exposição do olhar das crianças sobre o córrego. Chama a atenção o fato de o projeto valorizar a articulação com outras questões da 
região, como a proposta de relacionamento com a cooperativa de reciclagem e a relação com o Rio Tietê (que se encontra com o córrego em um dos bairros que está em sua região de várzea e constantes enchentes). O segundo projeto tinha como objetivo o plantio de plantas e árvores nas margens do córrego.

Por fim, o fórum do córrego Itupu não teve projeto elaborado, porque, de fato, esse fórum enfrentou consideráveis dificuldades para ser implementado por razões diversas. Dentre as variáveis do modelo e em comparação com os demais casos, podemos destacar o pequeno número de lideranças identificadas, bem como a baixa densidade de relacionamento entre elas, combinada com um número alto de moradores na região. Muitos domicílios tinham condições socioeconômicas muito vulneráveis, mas, além disso, o fato de ser uma área de ocupação recente e instável - com possibilidades recorrentes de realocação das moradias - teve repercussão com a dificuldade de mobilização para a participação nesse fórum. Pode-se notar que as variáveis presentes nos dois modelos sugerem caminhos para buscar explicações da diversidade de resultados da participação social empreendida nos fóruns. Como já foi dito, o resultado esperado da colaboração entre os participantes era a elaboração de um projeto para a preservação da limpeza dos córregos. Como vimos, esse resultado variou desde a formulação de dois projetos até o insucesso da proposta, sem a criação do fórum ou elaboração do projeto.

\section{Considerações Finais}

Com o objetivo de propor um modelo teórico-metodológico para a análise da efetividade da participação, foram contrapostas duas literaturas que, apesar de partirem de pressupostos distintos, trabalham com agendas paralelas: a atuação conjunta entre diferentes atores em instituições específicas de decisão e a implementação de políticas públicas.

Voltando o olhar para a efetividade da participação em termos de resultados do objetivo primeiro dos fóruns - a elaboração de projetos - a relação entre as variáveis estruturais que afetam o funcionamento institucional no modelo proposto oferece ferramentas relevantes para a análise. Ainda que os resultados aqui apresentados sejam parciais em relação à proposta de pesquisa mais ampla, podem-se destacar alguns ganhos metodológicos e analíticos.

Uma das possíveis contribuições metodológicas pode ser mesmo a forma 
de trabalhar a efetividade da participação com maior proximidade entre o objetivo da instância participativa e seu resultado concreto. Sem que isso questione os potenciais democratizantes das experiências participativas em si, procura-se de fato evitar problemas de causalidade remota nessa avaliação. $\mathrm{O}$ foco deste artigo foi reconhecer a incidência de fatores estruturais na dinâmica estabelecida entre os atores em instituições de participação, o que permitiu uma ampla compreensão sobre os resultados dessas instâncias.

Quanto à comparação das literaturas, a combinação entre elas parece ser um caminho promissor. Ainda que o desenho institucional seja a variável estrutural mais intuitiva para lidar com instituições participativas ou de ação coletiva, e por isso mesmo muito semelhante entre as duas abordagens, as demais variáveis podem ser trabalhadas de modo complementar.

O caso de maior integração entre as literaturas foi demonstrado a partir de uma combinação entre o agrupamento de três variáveis da literatura de participação social - organização da sociedade civil, vontade e cultura política - por um lado, e os atributos da comunidade (OSTROM, 2006), por outro. Mesmo que no presente artigo a vontade e cultura política não tenham sido aprofundadas, as outras variáveis mostraram grande potencial de diálogo.

Nesse sentido, a bibliografia de participação traz maior foco sobre a tradição associativa e características dos atores, enquanto atores sociais. Já a bibliografia de gestão de bens comuns parte de premissas do individualismo metodológico, que trata os atores enquanto indivíduos racionais. Isso favorece com que cada literatura tenha uma abordagem diferente sobre as características dos atores, mas que podem ser complementares na análise. De fato, a análise da rede de lideranças em contraste ao número estimado da população de cada bacia e suas condições socioeconômicas mostraram que nem sempre olhar só para um dos fatores confere uma explicação completa. Os fóruns analisados demonstraram que as variações de combinações entre essas características podem ser mais ou menos vantajosas para o funcionamento e resultado do fórum.

Por fim, a principal contribuição do modelo proposto pode ser a incorporação dos atributos do ambiente físico na análise das instâncias de participação. A análise do caso empírico revelou o importante papel desempenhado por essa variável. Os dois casos de fóruns com resultados de projetos mais destoantes foram justamente os casos com questões territoriais evidentes na condução do fórum. Primeiramente, no córrego Itupu, as condições foram menos favoráveis. Por conta da instabilidade da ocupação recente dos moradores da região, essa era a principal preocupação, e poucas 
lideranças foram identificadas na rede. De modo que o fórum não conseguiu ser criado, muito menos resultar em um projeto.

O córrego do Cruzeiro do Sul se destacou também por sua específica condição física com impactos sobre seu fórum. A divisão do terreno pelo qual passa o córrego em duas partes teve influência sobre as regras estabelecidas para o funcionamento do fórum, o reconhecimento e busca de pluralidade na representação das lideranças e mesmo sobre o local de reunião do fórum. Isto posto, foi o único fórum que incentivou a elaboração de mais de um projeto, e de fato teve dois projetos aprovados.

Assim, a partir das fundamentais contribuições das duas bibliografias analisadas, o presente trabalho apresentou um modelo comparativo de combinação das variáveis estruturais das duas vertentes, visando a um aprofundamento teórico-metodológico dos estudos de efetividade da participação social.

\section{Referência}

ABERS, Rebecca Neaera (org.). (2010). Água e Política: Atores, Instituições e Poder nos Organismos Colegiados de Bacia Hidrográfica no Brasil. São Paulo: Annablume.

ABERS, Rebecca Neaera; FORMIGA-JOHNSSON, Rosa Maria; FRANK, Beate; KECK, Margaret Elizabeth.; LEMOS, Maria Carmen.

(2009). Inclusão, deliberação e controle: três dimensões de democracia nos comitês e consórcios de bacias hidrográficas no Brasil. Ambiente \& Sociedade, vol. XII, n. 1.

AVRITZER, Leonardo.

(2008). Instituições participativas e desenho institucional: algumas considerações sobre a variação da participação no Brasil democrático. Opinião Pública, v. 14, n. 1.

(1994). Modelos de sociedade civil: uma análise da especificidade do caso brasileiro. In: Leonardo Avritzer (Orgs.); Sociedade Civil e Democratização. Belo Horizonte: Livraria Del Rey Editora.
BRESSER-PEREIRA, Luis Carlos.

(1997). A reforma do Estado nos anos 1990: lógica e mecanismos de controle. Cadernos MARE, $\mathrm{n}^{\circ} 1$.

BOSCHI, Renato Raul.

(1987). A arte da associação: Política de base e Democracia no Brasil. São Paulo: Vértice / Editora Revista dos Tribunais; Rio de Janeiro: Instituto Universitário de Pesquisas do Rio de Janeiro.

CAPELLA, Ana Cláudia Niedhardt.

(2008). Menos governo e mais governança? Repensando a lógica da ação estatal. $6^{\circ}$ Encontro da Associação Brasileira de Ciência Política $(A B C P)$. Campinas, Universidade de Campinas.

CARLOS, Euzineia; SILVA, Marta Zorzal.

(2005). Associativismo, participação e políticas públicas. Política \& Sociedade, n.9.

COELH0, Vera S. P.; FERRAZ, Alexandre; FANTI, Fabíola; RIBEIRO, Meire.

(2010). Mobilização e participação: um estudo sobre as dinâmicas de conselhos de saúde 
da cidade de São Paulo. In: Leonardo Avriter (Org.); A dinâmica da participação local no Brasil. São Paulo: Cortez.

COELH0, Vera Schattan Ruas Pereira.; FAVARETO, Arilson.

(2012). Conexões entre participação, democracia e desenvolvimento: investigação dos impactos políticos e distributivos da participação social. In: Adrian Gurza Lavalle (Org.); Horizonte da política: questões emergentes e agendas de pesquisa. São Paulo: Editora Unesp: Cebrap.

CORTES, Soraya Vargas.

(2011). As diferentes instituições participativas existentes nos municípios brasileiros. In: Roberto Rocha Pires (Org); Efetividade das instituições participativas no Brasil: estratégias de avaliação. Brasília: Ipea.

DAGNIN0, Evelina (Orgs).

(2012). Sociedade civil e espaços públicos no Brasil. São Paulo: Editora Paz e Terra.

GUARNIERI, Fernando; MESQUITA， Lara; RODRIGUES, Maira.

(2010). Relatório analítico apresentando os resultados da segunda etapa do trabalho de prestação de serviços técnicos especializados para capacitação dos técnicos da MC para a implementação das estratégias de governança colaborativa. São Paulo: CEBRAP.

GUARNIERI, Fernando; MESQUITA, Lara; RODRIGUES, Maira.

(2009). Relatório Sintese do Projeto Piloto: Estratégias de Organização e Articulação com a Comunidade do Programa Córrego Limpo. São Paulo: CEBRAP.

GURZA LAVALLE, Adrian.

(2011). Participação: valor, utilidade, efeitos e causa. In: Roberto Rocha Pires (Org); Efetividade das instituições participativas no Brasil: estratégias de avaliação. Brasília: Ipea.

GURZA LAVALLE, Adrian; CASTELLO, Graziela; BICHIR, Renata Mirandola.

(2006). Os bastidores da Sociedade Civil Protagonismos, Redes e Afinidades no Seio das Organizações Civis. São Paulo: CEBRAP.
HARDIN, Garret.

(1868). The tragedy of commons. Science, s.l., n.162, p.1243-1248.

IFFLY, Catherine.

(2010). Transformar a metrópole - Igreja católica, territórios e mobilizações sociais no Brasil, 1970-2000. São Paulo: Editora UNESP.

IMPERIAL, Mark.

(2005). Using Collaboration as a Governance Strategy: Lessons From Six Watershed Management Programs. Administration \& Society.

ISUNZA VERA, Ernesto; GURZA LAVALLE, Adrian.

(2012). Arquitetura da participação e controle democráticos no Brasil e no México. Novos Estudos Cebrap, 92.

KISER, Larry; OSTROM, Elinor.

(2000). The Three worlds of action: A metatheoretical synthesis of institutional approaches. In: Michael McGinnis (Ed.); Polycentric games and institutions: readings from the Workshop in Political Theory and Policy Analisys. The University of Michigan Press.

LE GALÈS, Patrick.

(2011). Urban Governance in Europe: What is Governed. In: Gary Bridge; Sophie Watson (Org.); The new Blackwell Companion to the City.

MARQUES, Eduardo César Leão.

(2003). Government, Political Actors and Governance in Urban Policies in Brazil and São Paulo: Concepts for a Future Research Agenda. Brazilian Political Science Review, 7 (3), p. 8-35.

MOURA, Tatiana Whately de.

(2011). Lei Seca e Segurança Pública: Problemas e Alternativas de Ação Coletiva. Dissertação de mestrado apresentada a Faculdade de Filosofia, Letras e Ciências Humanas, da Universidade de São Paulo. 
OLSON, Mancur.

(1999). A Lógica da Ação Coletiva: os benefícios públicos e uma teoria dos grupos sociais. São Paulo: Editora da Universidade de São Paulo.

OSTROM, Elinor.

(2009). A Polycentric Approach for Coping with Climate Change. Policy Research, Working Paper 5095.

(2006). Governing the Commons: the evolution of institutions for collective action. New York. Cambridge University Press.

(2005). Understanding institutional diversity. Princeton: Princeton University Press.

(1999). Institutional Rational Choice: an assessment of the institutional development and analysis. In: Paul Armand Sabatier. (Ed.); Theories of Policy Process: theoretical lenses on public policy. Bolder, Colorado: Westview Press.

(1998). A behavioural approach to the rationalchoice theory of collective action. American Political Science Review, vol. 92, p.1-22.

PIERRE, Jon.

(2011). The Politics of Urban Governance. Londres: Palgrave McMillan.

ROMÃo, Wagner de Melo.

(2010). Nas franjas da sociedade política: estudo sobre o orçamento participativo. Tese de doutorado apresentada a Universidade de São Paulo.

SILVA FILH0, José Carlos Lázaro; KÜCHLER, Johannes; NASCIMENTO, Luis Felipe; ABREU, Mônica Cavalcanti Sá de.
(2009). Gestão Ambiental Regional: usando o IAD Framework de Elinor Ostrom na 'Análise Política' da Gestão Ambiental na Região Metropolitana de Porto Alegre. Revista Organizações \& Sociedade. Salvador, v. 16, n. 51, p. 609-627.

SOUSA SANTOS, Boaventura de; AVRITZER, Leonardo.

2003. Introdução: para ampliar o cânone democrático. In: Boaventura de Sousa Santos (0rg.); Democratizar a democracia: os caminhos da democracia participativa. Rio de Janeiro: Civilização Brasileira.

\section{STOKER, Gerry.}

(1998). Governance as theory: five propositions. International Social Science Journal, vol. 50, issue 155 .

UNIVERSITY OF COLORADO - DENVER. Institutional Analysis and Development (IAD) Framework. Disponivel em: http:// www.ucdenver.edu/academics/colleges/SPA/ BuechnerInstitute/Centers/WOPPR/IAD/ Pages/default.aspx. Acesso em agosto de 2011.

\section{Recebido em}

janeiro de 2014

\section{Aprovado em}

junho de 2015 